\title{
Investigation of Corrosion Behaviour of Aluminium Alloy Subjected to Laser Shock Peening without a Protective Coating
}

\author{
U. Trdan and J. Grum \\ Faculty of Mechanical Engineering, University of Ljubljana, Askerceva Cesta 6, 1000 Ljubljana, Slovenia \\ Correspondence should be addressed to U. Trdan; uros.trdan@fs.uni-lj.si
}

Received 29 September 2015; Revised 15 November 2015; Accepted 16 November 2015

Academic Editor: Ying Li

Copyright ( 2015 U. Trdan and J. Grum. This is an open access article distributed under the Creative Commons Attribution License, which permits unrestricted use, distribution, and reproduction in any medium, provided the original work is properly cited.

The effect of shock waves and strain hardening of laser shock peening without protective coating (LSPwC) on alloy AA 6082T651 was investigated. Analysis of residual stresses confirmed high compression in the near surface layer due to the ultrahigh plastic strains and strain rates induced by multiple laser shock waves. Corrosion tests in a chloride environment were carried out to determine resistance to localised attack, which was also verified on SEM/EDS. OCP transients confirmed an improved condition, that is, a more positive and stable potential after LSPwC treatment. Moreover, polarisation resistance of the LSPwC treated specimen was by a factor of 25 higher compared to the untreated specimen. Analysis of voltammograms confirmed an improved enhanced region of passivity and significantly smaller anodic current density of the LSPwC specimen compared to the untreated one. Through SEM, reduction of pitting attack at the LSPwC specimen surface was confirmed, despite its increased roughness.

\section{Introduction}

Aluminium alloys of Al-Mg-Si system (6xxx series) are frequently used in industrial applications due to their low density, favourable mechanical properties, and high corrosion resistance $[1,2]$. Surface integrity and corrosion resistance play a major role in the stability of mechanical parts exposed to work under demanding conditions. However, despite the general high corrosion resistance of aluminium alloys, localised corrosion attack in aggressive environment often occurs. Especially in chloride environment, precipitation hardened $\mathrm{Al}$ alloys tend to show increased susceptibility to pitting corrosion and stress corrosion cracking $[3,4]$. Therefore, an adequate surface protection is frequently essential and is usually provided by various types of coatings [57] or in cases in which mechanical and microstructural enhancements are required, with different surface engineering processing techniques. In recent years, laser processing methods, such as laser surface remelting $[4,8]$ and laser shock peening $[9,10]$, have attracted interest because of their ability to improve the characteristics of aluminium alloys.
Laser peening (LSP) is an innovative surface treatment that is mostly applied to improve fatigue strength and fatigue crack initiation life through the creation of compressive residual stresses in the surface layer [11-13]. The basic idea of laser driven shock waves was first recognised and explored in the early 1960s [14]. When processing the material surface with an intense laser pulse with appropriate characteristics, the material's surface is vaporised and reaches temperatures of $10^{4 \circ} \mathrm{C}$ or more, which produces plasma. Plasma confined in water produces shock impact waves, which, in turn, produce considerable densification of dislocations and generation of compressive residual stresses of high gradient [15]. Chu et al. [16] validated the dislocation density after laser peening using an empirical equation. The results confirmed laser peening as a potential method of obtaining a high density of dislocations for improving fatigue resistance. Lavender et al. [17] confirmed the beneficial effect of laser peening on the life of a cold pilger die, due to deeper compressive residual stresses.

In practice, LSP has already been shown to produce higher compressive residual stresses and much greater depths 


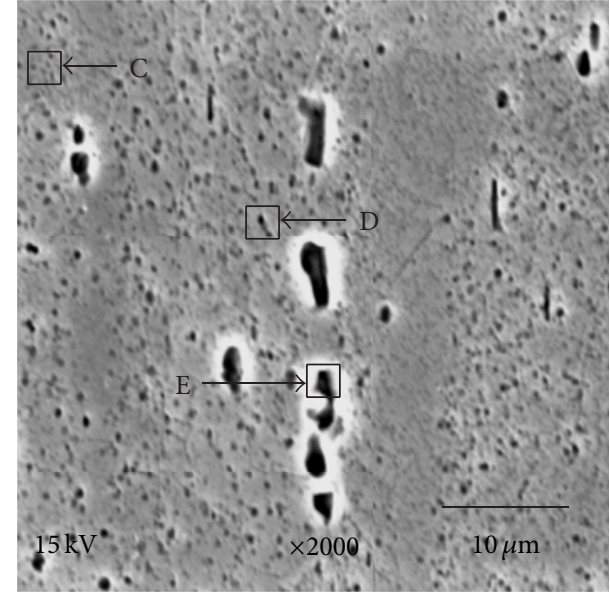

(a)

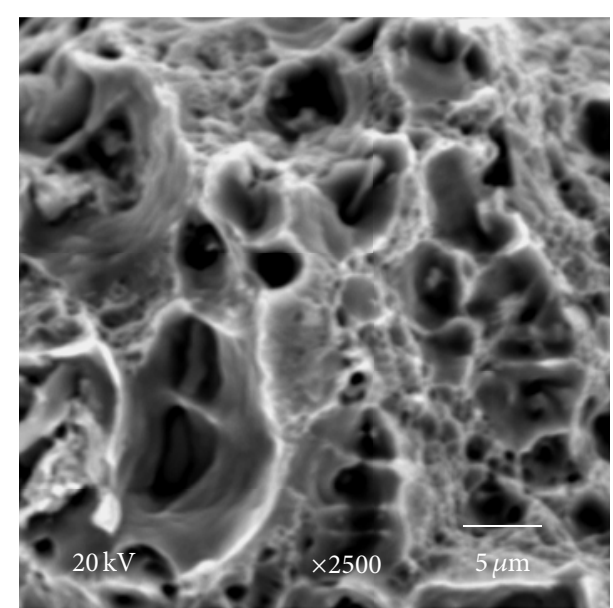

(b)

FIgURE 1: (a) Microstructure and (b) fractography of the investigated aluminium alloy.

comparable to conventional shot peening (SP) [18]. In addition, after the SP process, the surface of the metal component can be damaged and distorted, while after LSP the surface of the treated component is essentially unaffected [19]. Hatamleh et al. [9] confirmed the lower corrosion susceptibility of laser peened friction stir welded 7075 aluminium joints in a $3.5 \% \mathrm{NaCl}$ solution. Sano et al. [20] also confirmed the applicability of LSP to improve stress corrosion cracking. Trdan et al. $[2,21]$ concluded that there was a lower pit density on LSP-ed 6xxx aluminium alloys after anodic polarisation corrosion tests. García-Alonso et al. [22] confirmed that the lower roughness of alumina film $\mathrm{Al}_{2} \mathrm{O}_{3}$ enables enhanced corrosion resistance with higher pitting/breakdown potential. Moreover, Lee et al. [23] determined that there was improved corrosion resistance in a chloride medium after ultrasonic peening due to the decreased roughness compared to the as-received specimen.

In this paper, we present laser shock peening without protective coating ( $\mathrm{LSP}$ wC) effects on the surface integrity and corrosion resistance of 6082 aluminium alloy. We first quantified the degree of strain hardening effects of LSPwC using surface roughness and residual stress analysis. Furthermore, corrosion resistance in aggressive chloride environment was evaluated using open circuit potential (OCP) measurements, micropolarisation (LPR), and linear voltammetry measurements. Surface condition after corrosion tests was also characterised using an SEM.

\section{Experimental}

For the study, specimens of aluminium alloy AA 6082-T651 were cut into $8 \mathrm{~mm}$ thick discs from a $40 \mathrm{~mm}$ diameter drawn rod. The heat treatment T-651, which consists of solution heat treatment $\left(540^{\circ} \mathrm{C}\right)$ and artificial ageing at $160^{\circ} \mathrm{C}(10 \mathrm{~h})$, produced a microstructure with a large number of phase precipitates, that is, intermetallic particles, which increases the material hardness and strength.
TABLE 1: EDS results/chemical composition of the precipitates (wt\%).

\begin{tabular}{lccccccccc}
\hline Area & $\mathrm{Mg}$ & $\mathrm{Si}$ & $\mathrm{Pb}$ & $\mathrm{Mn}$ & $\mathrm{Fe}$ & $\mathrm{Cr}$ & $\mathrm{Zn}$ & $\mathrm{Cu}$ & $\mathrm{Al}$ \\
\hline $\mathrm{C}$ & - & - & - & 0.35 & 0.24 & - & - & - & bal. \\
$\mathrm{D}$ & - & - & - & 0.49 & 0.42 & - & 0.63 & 0.32 & bal. \\
$\mathrm{E}$ & 0.40 & 0.55 & - & 0.60 & 0.21 & - & - & - & bal. \\
\hline
\end{tabular}

Microstructure analysis and the chemical composition of the precipitates were established using an SEM JEOL JXA8600M using three EDS spectrographs for a microchemical analysis (Figure 1 and Table 1).

Laser surface treatment was carried out using the method of closed ablation without protective coating (LSPwC), with Q-switched Nd:YAG laser of $1064 \mathrm{~nm}$ and a power density of $10.75 \mathrm{GW} / \mathrm{cm}^{2}$. A pulse density of 900 pulses $/ \mathrm{cm}^{2}$ was equivalent to final cumulative fluence of $1.71 \mathrm{~kJ} / \mathrm{cm}^{2}$. Pulse duration of $10 \mathrm{~ns}$ (FWHM) and a repetition rate of $10 \mathrm{~Hz}$ were chosen. A schematic presentation of the LSPwC process is given in Figure 2.

Prior to and after LSPwc treatment, the surface integrity was characterised by investigation of the surface topography and microstructure using an Olympus SZX-10 and a Meiji MT-7100 microscope, respectively. Afterwards, the surface profile and roughness measurements were conducted with a profile meter Surtronic 3+ Taylor/Hobson Pneumo using a unified Gaussian filter $\left(\lambda_{c}=0.8 \mathrm{~mm}\right)$.

Residual stresses (RS) were measured in accordance with ASTM E 837 standard [24], where strain gages CEA-06-062UM along with RS-200 Milling Guide, Vishay Measurement Group, were used. Strains measurements were performed by incremental hole drilling measurements, increment being $0.1 \mathrm{~mm}$, whereas 10 measurements were performed. In order to obtain reliability of the measurements, two separate measurements were performed on both untreated and LSPwC specimens, respectively. The final RS profile was determined 


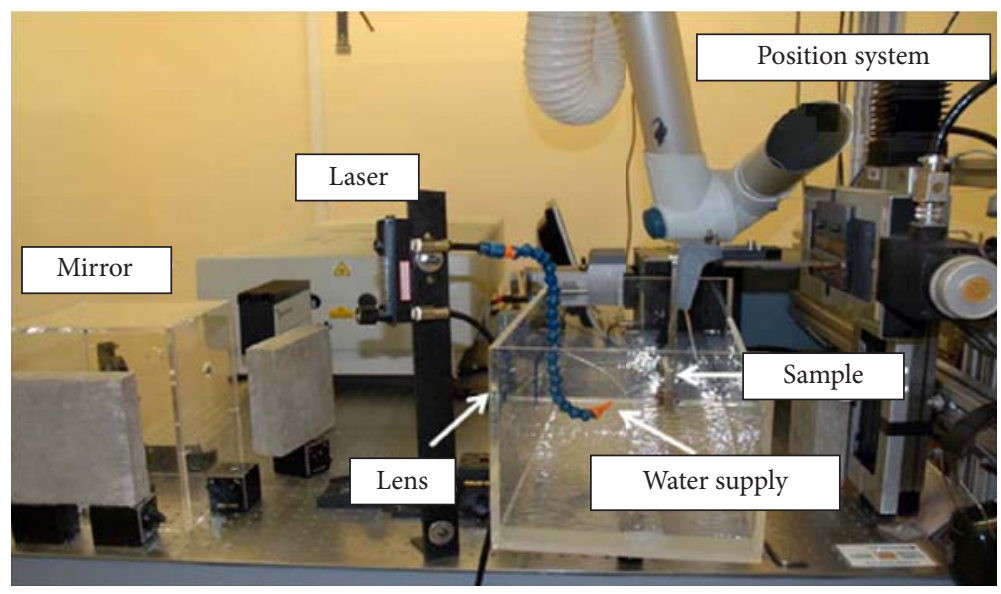

(a)

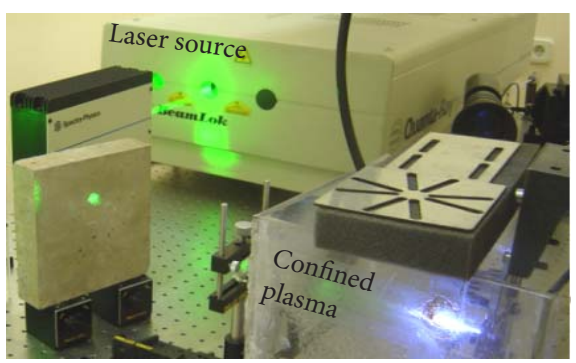

(b)

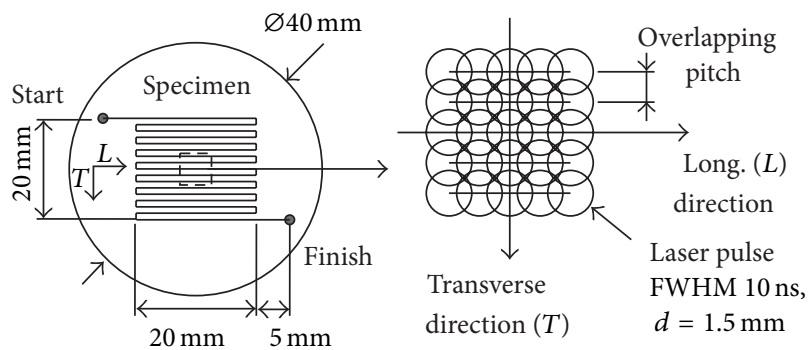

(c)

FIGURE 2: (a) Experimental LSPwC set-up; (b) generation of confined plasma during LSPwC and (c) schematic presentation of the LSPwC surface scan/sweep.

by the integral method, using $\mathrm{H}$-drill version 3.10 software [25].

This method enables low sensitivity to experimental errors and high resolution of calculated residual stresses. Despite usage of incremental drilling of $0.1 \mathrm{~mm}$ and the first strain measurement obtained at this depth, the integral method provides first RS data on a specific depth of $33 \mu \mathrm{m}$. Nevertheless, this method is the right choice when measuring rapidly varying residual stresses and provides a separate evaluation of residual stress within each increment of depth used during the hole drilling measurements [26]. However, the sensitivity of the calculated stresses is also the most severe. Therefore, according to $\mathrm{H}$-drill recommendation automatic smoothing was chosen with the Tikhonov regularisation scheme to enhance stability and resistance to experimental errors and stabilisation of the Integral Method stress calculation [25].

An investigation of corrosion behaviour was conducted in

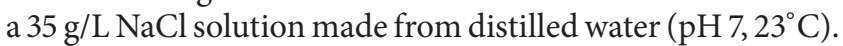
Before the tests, the samples were carefully cleaned in alcohol and deionised water for $3 \mathrm{~min}$ each and pretested to ensure the repeatability of the measurements. The electrochemical characteristics were evaluated using a potentiostat Voltalab 21, Radiometer Analytical, and three-electrode CEC/TH cell with a Pt counter and a reference calomel electrode (SCE = $+244 \mathrm{mV}$ versus SHE). In order to stabilise the surface, the specimens were immersed in the medium for 60 min during which the open circuit potential (OCP) was monitored. Afterwards, micropolarisation (LPR) tests were performed by disturbing the system with $\pm 20 \mathrm{mV}$ versus $E_{\text {corr }}$ at a scan rate of $0.1 \mathrm{mV} / \mathrm{s}$. Afterwards, linear voltammetry was started at a potential of $-1800 \mathrm{mV}_{\mathrm{SCE}}$, which was shifted up to $-500 \mathrm{mV}_{\mathrm{SCE}}$ at $10 \mathrm{mV} / \mathrm{s}$. These potential ranges were chosen in order to observe cathodic corrosion phenomena at lower potentials. Final validation of the surface condition after corrosion was performed using a scanning electron microscope equipped with EDS microanalysis hardware.

\section{Results and Discussion}

3.1. Surface Roughness. Microsection comparison in both of the longitudinal $(L)$ and transverse $(T)$ directions of the LSPwC surface sweep (Figure 3) showed rather similar surface conditions in both directions. However, higher coincidental deviation of the surface profile was obtained in the transversal direction of the laser beam movement. The calculated crater depth (peak-to-peak amplitude) after LSPwC treatment was similar in both directions, that is, $12 \pm 4.24 \mu \mathrm{m}$ in the $L$ direction and $18.5 \pm 2.12 \mu \mathrm{m}$ in the $T$ direction, respectively. However, the crater area was about $220 \mu \mathrm{m}^{2}$ larger in the $T$ than in the $L$ direction $\left(1088.12 \mu \mathrm{m}^{2}\right.$ versus $867.92 \mu \mathrm{m}^{2}$ ).

Due to the preliminary preparation of the specimens with a cutter and the LSPwC surface sweep direction, it 


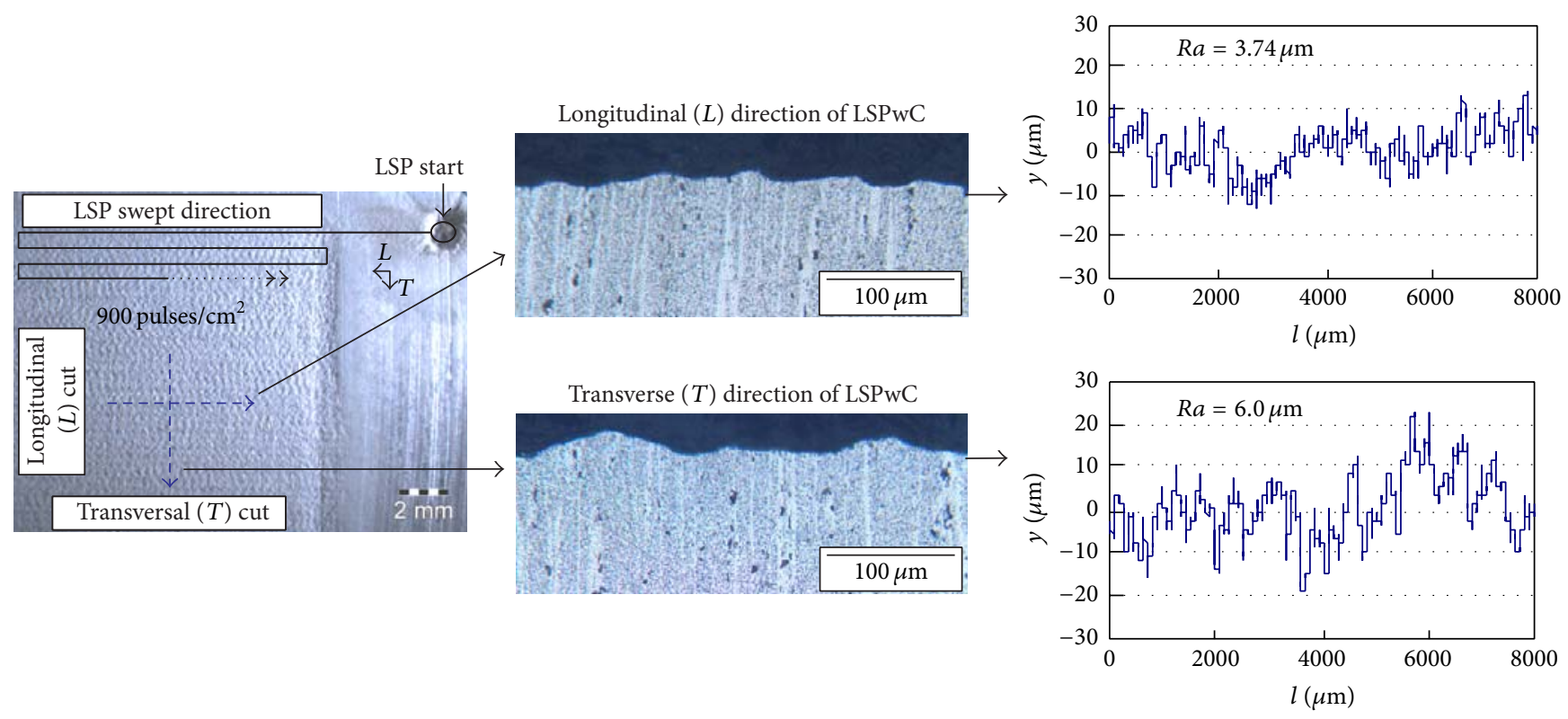

FIgURE 3: Presentation of LSPwC surface scan and microsection of LSPwC treated sample with resulting surface profile.

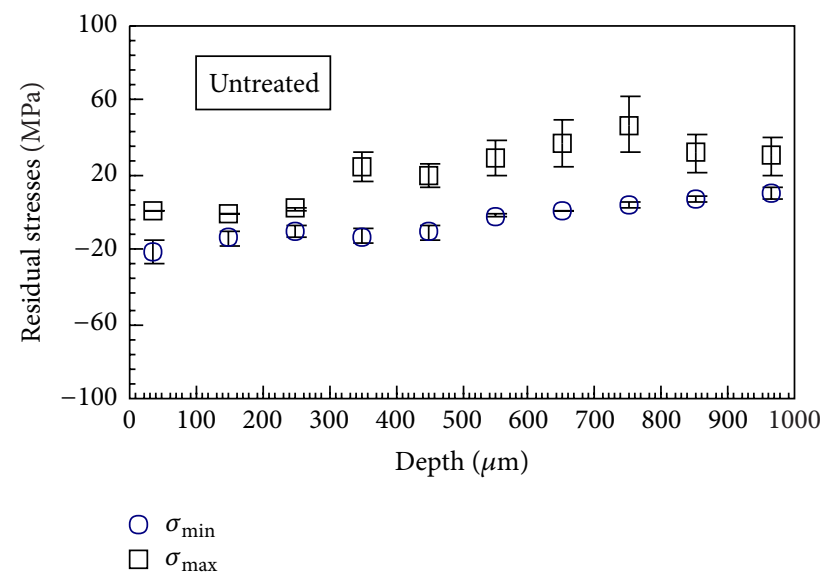

(a)

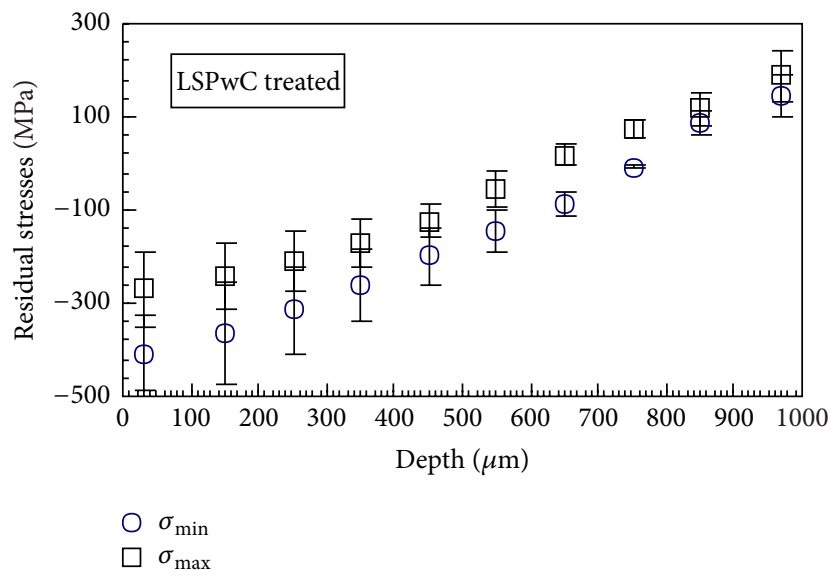

(b)

FIGURE 4: Hole drilling principal residual stresses $-\sigma_{\mathrm{RS}}$.

TABLE 2: Surface roughness results.

\begin{tabular}{lcc}
\hline & $L$ direction & $T$ direction \\
\hline Untreated & 0.72 & 0.81 \\
LSPwC & 3.74 & 6.00 \\
\hline
\end{tabular}

was decided to establish surface profiles in the longitudinal $(L)$ and transverse $(T)$ directions by mean values of the arithmetic roughness, $\overline{R a_{L}}$ and $\overline{R a_{T}}$, using three profile measurements. The results of surface roughness are presented in Table 2.

The roughness $(R a)$ of the untreated specimen without laser peening was $0.72 \mu \mathrm{m}$ in the $L$ direction and $0.81 \mu \mathrm{m}$ in the $T$ direction. After LSPwC treatment, $R a$ increased to $3.74 \mu \mathrm{m}$ in $L$ direction and $6.00 \mu \mathrm{m}$ in $T$ measurement direction.
The increase in surface roughness at the LSPwC specimen is a consequence of numerous laser-beam interactions with the specimen surface due to pulse overlapping and the cumulative action of induced plasma and shock waves at the interaction point [15].

3.2. Residual Stresses. The principal residual stresses (RS) as a function of depth are shown in Figure 4. The principal residual stresses $\sigma_{\max }$ and $\sigma_{\min }$ represent the stress component in the longitudinal $(L)$ and transverse $(T)$ directions of the LSPwC-scan, respectively. The residual stresses in the initial state specimen were about the same in both longitudinal and transverse directions, and they ranged from $+47 \pm 15 \mathrm{MPa}$ to $-21 \pm 7 \mathrm{MPa}$.

Analysis of the principal RS after LSPwC treatment has shown a predominantly compressive character. It was 


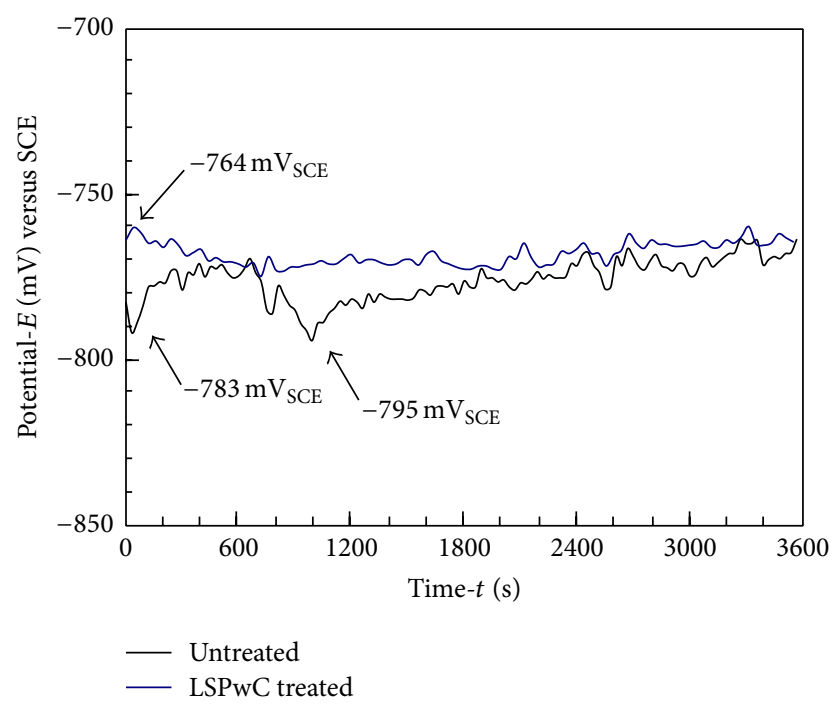

Figure 5: Open circuit potential $\left(E_{\text {ocp }}=f[t]\right)$ curves in $35 \mathrm{~g} / \mathrm{L} \mathrm{NaCl}$ solution.

observed that in the case of LSPwC treatment $\sigma_{\max }$ and $\sigma_{\text {min }}$ changed to the tensile state after reaching depths of approximately $620 \mu \mathrm{m}$ and $770 \mu \mathrm{m}$, respectively.

Thus, higher hardening depth (higher compression) due to shock waves was obtained with minimal principal stresses, that is, in the $T$ direction of the LSPwC sweep direction. Furthermore, the highest compressive RS at the near surface $(33 \mu \mathrm{m})$ after LSPwC were obtained in the transverse, that is, advancing direction $\sigma_{\min }=-407 \pm 81 \mathrm{MPa}$. Afterwards, a constant decrease with a constant gradient is observed up to a final depth of $967 \mu \mathrm{m}$. Due to excessive shock wave pressure at the specimen's surface, the highest compressive RS exceeded the "quasi" static tensile strength $\left(\sigma_{m}=327 \mathrm{MPa}\right)$ of the base material. Furthermore, it was observed that higher compressive RS are achieved in the transverse direction throughout analysed depth. Similar RS results were obtained in our previous publications $[2,27]$ and are consistent with the results of other publications $[20,28,29]$.

3.3. Corrosion Analysis. In order to evaluate the surface conditions and to characterise the modification of the oxide layer due to plasma ablation of the LSPwC specimen treated with 900 pulses $/ \mathrm{cm}^{2}$, no additional grinding or polishing of the surfaces was performed. From the OCP transients $\left(E_{\text {ocp }}=\right.$ $f[t])$ in Figure 5, it is obvious that the untreated specimen exhibits more negative values compared to the LSPwC specimen. Moreover, relatively stable and higher potential values are obtained after LSPwC, indicating an equilibrium state at which the rate of oxidation $\left(I_{\mathrm{Ox}}\right)$ equals that of reduction $\left(I_{\text {Red }}\right)$. More stable and more positive behaviour after LSPwC treatment is most likely attributed to the formation of a modified aluminium oxide and nanostructure in the treated area that enhances the material's corrosion resistance and mechanical properties [2].

The results of the micropolarisation test at an applied potential $\pm 20 \mathrm{mV}$ versus $E_{\text {ocp }}$ are shown in Figure 6 . The

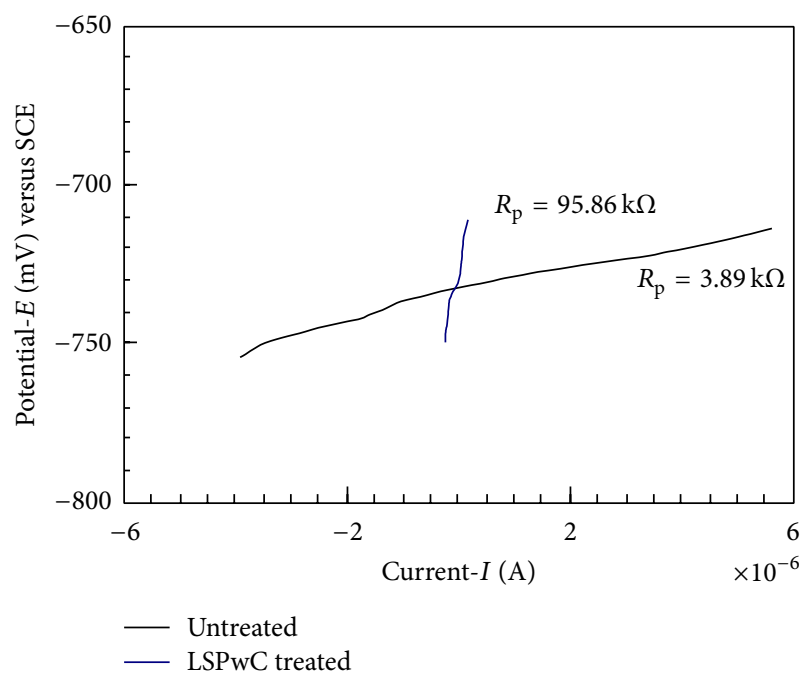

FIGURE 6: Micropolarisation curves of the untreated and LSPwC specimen.

results confirmed a smaller variation in electrical current for the LSPwC specimen, indicating higher polarisation resistance. Micropolarisation showed good correlation with the OCP measurements, indicating the strong influence of preliminary LSPwC surface treatment. Moreover, the results confirmed almost 25 times higher polarisation resistance of the LSPwC treated specimen compared to the untreated one $(95.86 \mathrm{k} \Omega$ versus $3.89 \mathrm{k} \Omega$ ).

The results presented in this study are consistent with other studies. For example, Peyre et al. [30] confirmed the ennoblement of $E_{\text {ocp }}$ by means of an anodic shift after LSP treatment, whereas more stable $E_{\text {ocp }}$ values were observed in the untreated specimen, suggesting faster stabilisation of the passive film due to better surface homogeneity. However, in their investigation, an ablative protective coating was used, which caused only a pure mechanical effect of LSP (shock waves), that is, no thermal effect, which modifies the thin surface film of the processed part. In the present study, LSP was performed without a protective overlay (LSPwC) on the surface of the processed specimens. Thus, heat generated from the laser pulses affects the surface state due to surface melting and plasma ionisation. Pariona et al. [8] also reported similar results of nobler corrosion potential with enhanced polarisation resistance after laser surface melting of $\mathrm{Al}-$ 1.5 wt.\% Fe alloy. Another similar observation was reported by Yue et al. [31], where the effect of laser surface treatment was investigated for $7075 \mathrm{Al}$ alloy. The results demonstrated a chemically stable phase after laser treatment, which protected the matrix against corrosion.

Figure 7 shows linear voltammograms of the untreated and LSPwC treated specimen, where the scanning cycle of potentials started at $-1.8 \mathrm{~V}_{\mathrm{SCE}}$ and extended up to the anodic value of $-0.5 \mathrm{~V}_{\mathrm{SCE}}$ with a scan rate of $10 \mathrm{mV} / \mathrm{s}$. Voltammetry techniques are efficient and versatile electrochemical technique, which are used in the study of systems that involve reactions of reduction-oxidation in electrolytic solutions [32]. Voltammograms for both untreated and LSPwC treated 


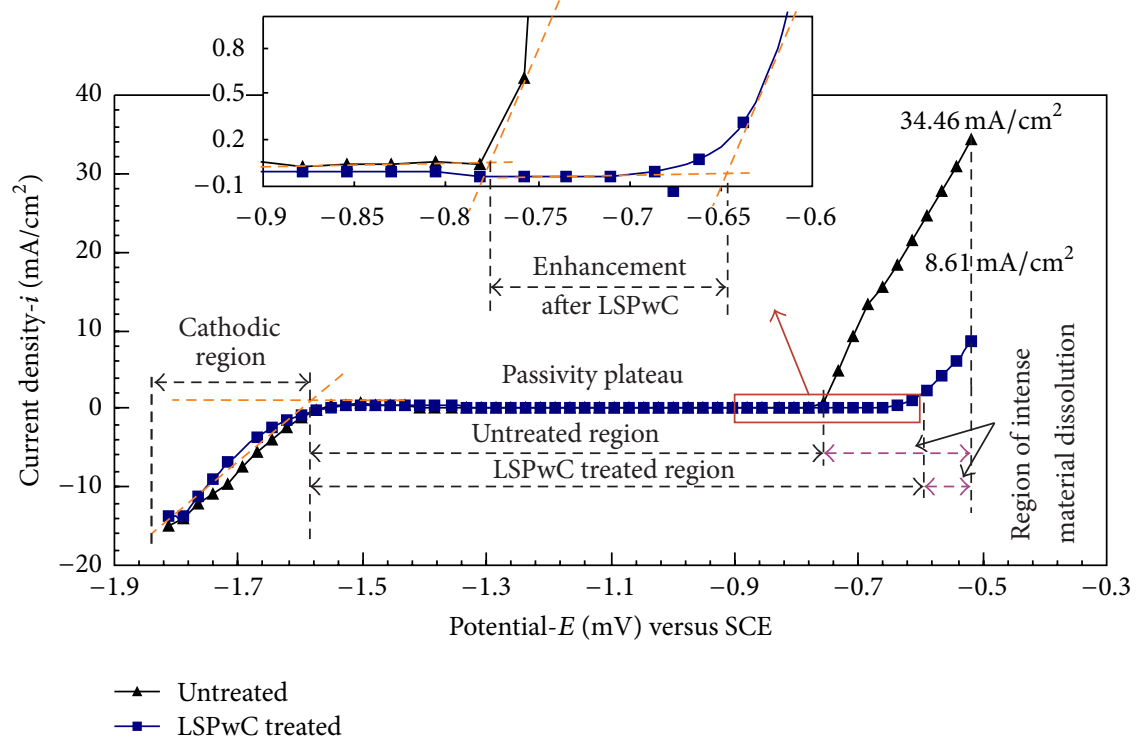

FIGURE 7: Linear voltammograms of the untreated and LSPwC treated specimen.

specimens confirmed a relatively high cathodic current $\left(-14 \mathrm{~mA} / \mathrm{cm}^{2}\right)$ at the stating potential of $-1.8 \mathrm{~V}_{\mathrm{SCE}}$. Afterwards, a sharp decrease occurred due to formation of $\mathrm{Al}$ oxide at the specimen's surface at the potential near $-1.6 \mathrm{~V}_{\mathrm{SCE}}$ where the current density was practically zero, which is characteristic of a passivity plateau. The current density in the forward anodic scan in the passive region stayed practically unchanged up to $-0.782 \mathrm{~V}_{\mathrm{SCE}}$ for the untreated specimen. However, in the case of the LSPwC treated specimen, the region of passivity greatly increased, that is, up to a potential of $-0.64 \mathrm{~V}_{\mathrm{SCE}}$. The rapid increase in the subsequent anodic potential represents the transpassive region, which is directly associated with the dissolution of Al alloy.

Apparently, despite increased roughness, the LSPwC treated specimen exhibited an improved and extended region of passivity, indicating improved corrosion resistance compared to the untreated specimen. Furthermore, the anodic current at ending potential $\left(-0.5 \mathrm{~V}_{\mathrm{SCE}}\right)$ was 4 times lower after LSPwC treatment $\left(34.46 \mathrm{~mA} / \mathrm{cm}^{2}\right.$ versus $8.61 \mathrm{~mA} /$ $\mathrm{cm}^{2}$ ). Moreover, one should note that since laser treatment increased surface roughness, the active surface exposed to the medium was in fact larger than $1 \mathrm{~cm}^{2}$. Hence, the corrosion current density and corrosion rate of LSPwC treated specimen are in fact even smaller. As seen in Figure 8, the localised pitting attack is present in both specimens; nevertheless the intensity of pitting attack is more severe in the untreated one, with intense, widespread pitting attack. The pit shape in the untreated sample is mostly "semi-" circular or "semi-" elliptical (Figure 9), with diameters in the 100-300 $\mu \mathrm{m}$ range. However, after LSPwC treatment, significant modifications are obtained, with only a few smaller hemispherical anodic pits being observed.

It should be noted that cathodic corrosion and the accumulation of $\mathrm{OH}^{-}$ions occur at potentials more negative than $-1130 \mathrm{mV}_{\mathrm{SCE}}$, with pitting attack presented in the form of bright surface craters [33]. From all of the abovementioned, it is clear that LSPwC treatment clearly makes the penetration of water molecules, oxygen, and $\mathrm{Cl}^{-}$ions more difficult due to the development of compressive residual stresses in the near surface and an improved passive/oxide film after LSPwC treatment. Moreover, more positive corrosion potential, higher $R_{\mathrm{p}}$, and an extended region of passivity with reduced anodic current indicate a lower advance of corrosion in the LSPwC specimen in an aggressive chloride environment.

Peyre et al. [34] confirmed the anodic potential shift as a result of LSP surface modification, with better resistance to pitting attack. Krawiec et al. [35] confirmed an increase in the charge transfer and oxide film resistances at sites containing the matrix due to compressive residual stresses during the LSP process. Furthermore, in another study, Peyre et al. [30] showed that laser peening of 316L steel increased the content of $\mathrm{C}, \mathrm{O}$, and $\mathrm{H}$ by as much as $50-100 \%$ up to $0.4 \mu \mathrm{m}$ below the surface. It was suggested that the compressive residual stresses induced after LSP affect construction and growth of the passive film, indicating improved corrosion resistance.

Figure 10 shows the surface morphology of an untreated specimen after corrosion tests and the results of EDS analysis at point A. After breakdown of the passive layer, there is a pitting attack on both specimens due to dissolution of the anodic (negative) intermetallic particles. Panagopoulos et al. [36] reported the presence of two main intermetallic particles in the 6082 alloy, that is, the $\mathrm{Si}$ phase $\left(-170 \mathrm{mV}_{\mathrm{SCE}}\right)$ and $\mathrm{Mg}_{2} \mathrm{Si}$ phase $\left(-1190 \mathrm{mV}_{\mathrm{SCE}}\right)$.

In our study, EDS analysis of the microstructure (Figure 1) showed three second-phase intermetallic particles. The first intermetallic particles of the smallest diameter consisted of $\mathrm{Al}_{x}(\mathrm{Mn}, \mathrm{Fe})$, the second consisted of $\mathrm{Al}_{x}(\mathrm{Zn}$, $\mathrm{Mn}, \mathrm{Fe}$, and $\mathrm{Cu})$, and the third consisted of $\mathrm{Al}_{x}(\mathrm{Si}, \mathrm{Mn}$, $\mathrm{Mg}$, and Fe). Thus, it is evident that the localised corrosion attack in the form of a corrosion product is the result of cathodic corrosion at point $\mathrm{A}$ and localised dissolution of 


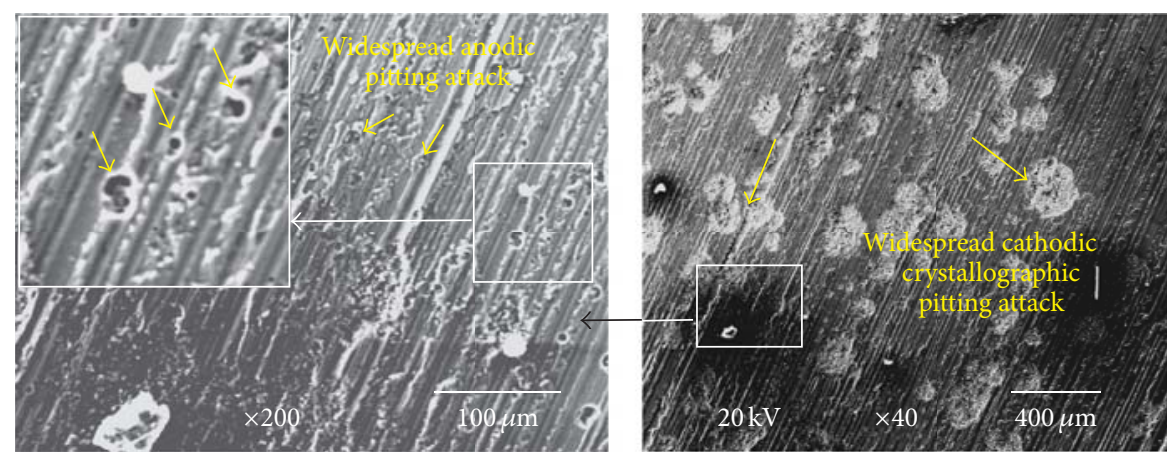

(a)
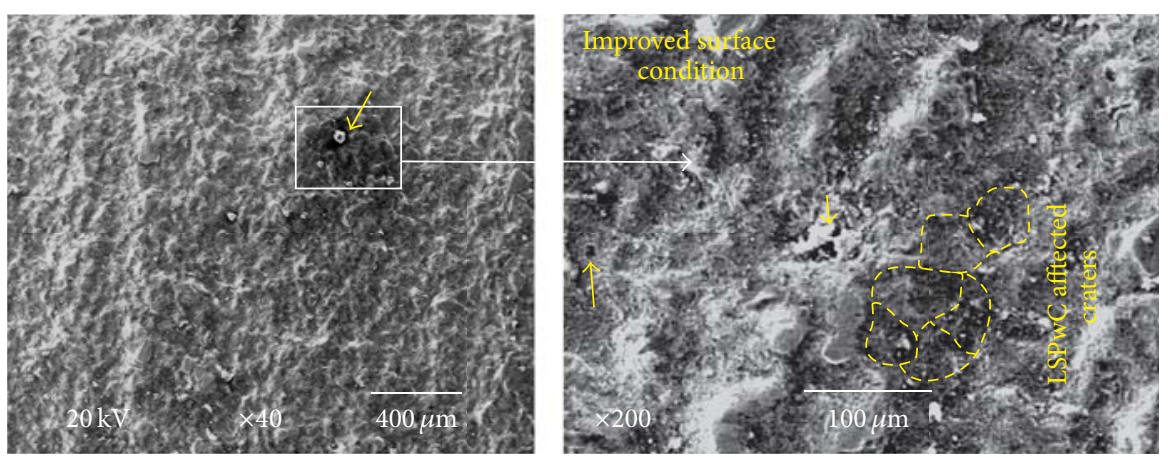

(b)

FIGURE 8: SEM/SEI images of the surface condition of the untreated and LSPwC treated specimen surfaces. (a) Untreated and (b) LSPwC treated specimen.

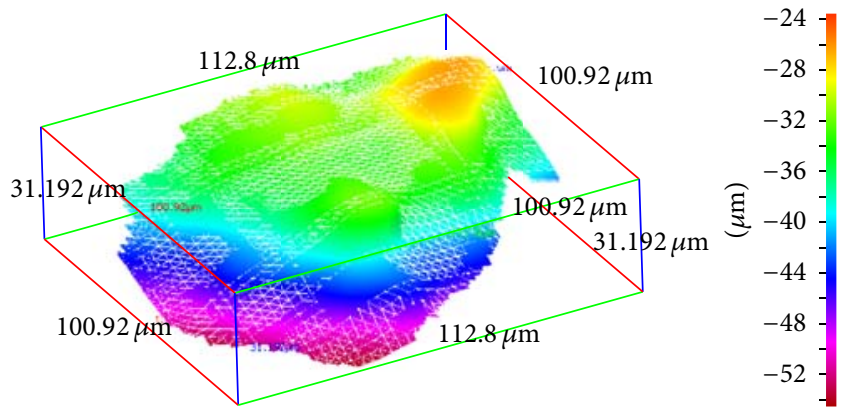

Figure 9: 3D presentation of "elliptical" corrosion pit in the untreated specimen.

second-phase particles $\mathrm{Al}_{x}(\mathrm{Si}, \mathrm{Mn}, \mathrm{Mg}$, and $\mathrm{Fe})$ at point $\mathrm{B}$ (Figure 10). The potential difference between the anodic particles $\mathrm{Al}_{x}(\mathrm{Si}, \mathrm{Mn}, \mathrm{Mg}$, and $\mathrm{Fe})$ and the surrounding $\mathrm{Al}$ matrix leads to local dissolution of the anodic particles. In the presence of smaller $\mathrm{Al}_{x}(\mathrm{Mn}, \mathrm{Fe})$ and $\mathrm{Al}_{x}(\mathrm{Zn}, \mathrm{Mn}, \mathrm{Fe}$, and $\mathrm{Cu}$ ) particles, which are cathodic to the 6082 alloy matrix, the corrosion process is just the opposite. As the potential of these two particles is nobler than the matrix, the $\mathrm{Al}$ matrix is preferentially corroding in an aggressive $\mathrm{NaCl}$ solution. Owing to distinctive local alkalisation, dissolution of the $\mathrm{Al}$ matrix occurs in the area of the more noble second-phase particles [37-39].

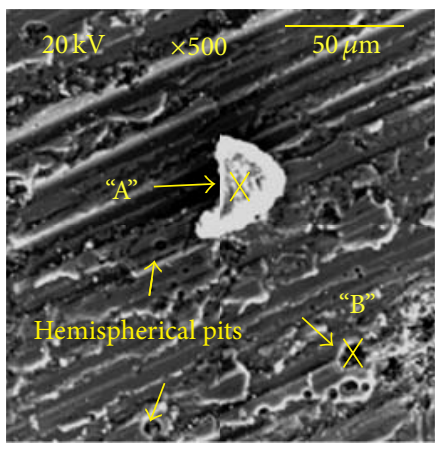

\begin{tabular}{lc}
\hline Element & (wt.\%) \\
\hline Al-K & 95.53 \\
Si-K & 0.61 \\
Zn-K & 0.41 \\
Mg-K & 0.95 \\
Na-K & 0.65 \\
Mn-K & 0.30 \\
Fe-K & 0.30 \\
Ti-K & 0.94 \\
Cr $+\mathrm{Cu}+\mathrm{Cl}$ & 0.30 \\
\hline Total & 100 \\
\hline
\end{tabular}

FIGURE 10: Untreated specimen's surface after corrosion and EDS results for point $\mathrm{A}$.

\section{Conclusion}

LSPwC surface treatment has turned out to be an effective method of inducing compressive residual stresses in the near surface layer of investigated Al alloy, with higher stress values in the advancing laser scan direction. However, surface roughness after LSPwC increased as a consequence of numerous laser ablation, plasma, and shock waves on the treated surface.

OCP transients confirmed more positive and stable potential values of the LSPwC treated specimen, indicating improved corrosion resistance. In addition, polarisation 
resistance of the $\mathrm{LSPwC}$ treated specimen in an aggressive chloride environment was up to 25 times higher compared to the untreated specimen. Voltammetry tests confirmed the improved characteristics after LSPwC, showing a larger region of passivity, a smaller transpassive region, and exceptionally reduced anodic current density compared to the untreated specimen.

Localised pitting corrosion attack was observed in both the untreated and LSPwC treated state. However, despite the increased roughness of the LSPwC specimen the extent of passivity occurred and localised pitting attack was reduced, which confirmed improved corrosion resistance. Improved resistance to localised corrosion is attributed to the transformed oxide film created due to ablation of the specimen surface during the laser peening process and high compressive residual stresses, both of which hinder corrosion progress.

\section{Conflict of Interests}

The authors declare that there is no conflict of interests regarding the publication of this paper.

\section{References}

[1] H. Ezuber, A. El-Houd, and F. El-Shawesh, "A study on the corrosion behavior of aluminum alloys in seawater," Materials and Design, vol. 29, no. 4, pp. 801-805, 2008.

[2] U. Trdan and J. Grum, "Evaluation of corrosion resistance of AA6082-T651 aluminium alloy after laser shock peening by means of cyclic polarisation and ElS methods," Corrosion Science, vol. 59, pp. 324-333, 2012.

[3] Z. Szklarska-Smialowska, "Pitting corrosion of aluminum," Corrosion Science, vol. 41, no. 9, pp. 1743-1767, 1999.

[4] T. M. Yue, L. J. Yan, and C. P. Chan, "Stress corrosion cracking behavior of Nd:YAG laser-treated aluminum alloy 7075," Applied Surface Science, vol. 252, no. 14, pp. 5026-5034, 2006.

[5] X. Nie, E. I. Meletis, J. C. Jiang, A. Leyland, A. L. Yerokhin, and A. Matthews, "Abrasive wear/corrosion properties and TEM analysis of $\mathrm{Al}_{2} \mathrm{O}_{3}$ coatings fabricated using plasma electrolysis," Surface and Coatings Technology, vol. 149, no. 2-3, pp. 245-251, 2002.

[6] A. Frignani, F. Zucchi, G. Trabanelli, and V. Grassi, "Protective action towards aluminium corrosion by silanes with a long aliphatic chain," Corrosion Science, vol. 48, no. 8, pp. 2258-2273, 2006.

[7] T. Liu, F. Zhang, C. Xue, L. Li, and Y. Yin, "Structure stability and corrosion resistance of nano- $\mathrm{TiO}_{2}$ coatings on aluminum in seawater by a vacuum dip-coating method," Surface and Coatings Technology, vol. 205, no. 7, pp. 2335-2339, 2010.

[8] M. M. Pariona, V. Teleginski, K. D. Santos et al., "Yb-fiber laser beam effects on the surface modification of Al-Fe aerospace alloy obtaining weld filet structures, low fine porosity and corrosion resistance," Surface and Coatings Technology, vol. 206, no. 8-9, pp. 2293-2301, 2012.

[9] O. Hatamleh, P. M. Singh, and H. Garmestani, "Corrosion susceptibility of peened friction stir welded 7075 aluminum alloy joints," Corrosion Science, vol. 51, no. 1, pp. 135-143, 2009.

[10] U. Trdan and J. Grum, "SEM/EDS characterization of laser shock peening effect on localized corrosion of $\mathrm{Al}$ alloy in a near natural chloride environment," Corrosion Science, vol. 82, pp. 328-338, 2014.

[11] P. Peyre, R. Fabbro, P. Merrien, and H. P. Lieurade, "Laser shock processing of aluminium alloys. Application to high cycle fatigue behaviour," Materials Science and Engineering A, vol. 210, no. 1-2, pp. 102-113, 1996.

[12] C. Rubio-González, J. L. Ocaña, G. Gomez-Rosas et al., "Effect of laser shock processing on fatigue crack growth and fracture toughness of 6061-T6 aluminum alloy," Materials Science and Engineering A, vol. 386, no. 1-2, pp. 291-295, 2004.

[13] G. Singh, M. Cortina, H. Millwater, and A. Clauer, "Probabilistic sensitivity analysis of a laser peening fatigue life enhancement process," International Journal of Structural Integrity, vol. 3, no. 3, pp. 210-235, 2012.

[14] B. P. Fairand and A. H. Clauer, "Laser generated stress waves: their characteristics and their effects to materials," in LaserSolid Interactions and Laser Processing, vol. 50 of AIP Conference Proceedings, pp. 27-42, American Institute of Physics, 1978.

[15] U. Trdan, J. A. Porro, J. L. Ocaña, and J. Grum, "Laser shock peening without absorbent coating (LSPwC) effect on 3D surface topography and mechanical properties of 6082-T651 Al alloy," Surface and Coatings Technology, vol. 208, pp. 109-116, 2012.

[16] J. P. Chu, J. M. Rigsbee, G. Banaś, and H. E. Elsayed-Ali, "Laser-shock processing effects on surface microstructure and mechanical properties of low carbon steel," Materials Science and Engineering A, vol. 260, no. 1-2, pp. 260-268, 1999.

[17] C. A. Lavender, S.-T. Hong, M. T. Smith, R. T. Johnson, and D. Lahrman, "The effect of laser shock peening on the life and failure mode of a cold pilger die," Journal of Materials Processing Technology, vol. 204, no. 1-3, pp. 486-491, 2008.

[18] G. Hammersley, L. A. Hackel, and F. Harris, "Surface prestressing to improve fatigue strength of components by laser shot peening," Optics and Lasers in Engineering, vol. 34, no. 4-6, pp. 327-337, 2000.

[19] A. H. Clauer, "Laser shock peening for fatigue resistance," in Surface Performance of Titanium, J. K. Gregory, H. J. Rack, and D. Eylon, Eds., pp. 217-230, TMS, Warrendale, Pa, USA, 1996.

[20] Y. Sano, M. Obata, T. Kubo et al., "Retardation of crack initiation and growth in austenitic stainless steels by laser peening without protective coating," Materials Science and Engineering A, vol. 417, no. 1-2, pp. 334-340, 2006.

[21] U. Trdan, J. Grum, J. A. Porro, and J. L. Ocana, "Analysis of residual stress and corrosion resistance of laser shock-processed 6012 and 6082 aluminium alloys," in The 17 International Symposium on Gas Flow, Chemical Lasers, and High-Power Lasers, vol. 7131 of Proceedings of SPIE, Lisboa, Portugal, April 2009.

[22] M. C. García-Alonso, M. L. Escudero, J. L. González-Carrasco, and J. Chao, "Effect of substrate roughness on the corrosion behaviour of the $\mathrm{Al}_{2} \mathrm{O}_{3}$ /MA 956 system," Biomaterials, vol. 21, no. 1, pp. 79-87, 2000.

[23] H.-S. Lee, D.-S. Kim, J.-S. Jung, Y.-S. Pyoun, and K. Shin, "Influence of peening on the corrosion properties of AISI 304 stainless steel," Corrosion Science, vol. 51, no. 12, pp. 2826-2830, 2009.

[24] ASTM International, "Standard test method for determining residual stresses by the hole drilling strain Gage method," ASTM E 837-08, ASTM International, West Conshohocken, Pa, USA, 2008.

[25] G. S. Schajer, “H-Drill User Manual, Version 3.10,” 2000-2007. 
[26] P. V. Grant, J. D. Lord, and P. S. Whitehead, Measurement Good Practice Guide No. 53: The Measurement of Residual Stresses by the Incremental Hole Drilling Technique, National Physical Laboratory, Teddington, UK, 2002.

[27] U. Trdan, J. L. Ocaña, and J. Grum, "Surface modification of aluminium alloys with Laser Shock Processing," Journal of Mechanical Engineering, vol. 57, no. 5, pp. 385-393, 2011.

[28] E. Maawad, Y. Sano, L. Wagner, H.-G. Brokmeier, and C. Genzel, "Investigation of laser shock peening effects on residual stress state and fatigue performance of titanium alloys," Materials Science and Engineering A, vol. 536, pp. 82-91, 2012.

[29] E. Maawad, H.-G. Brokmeier, L. Wagner, Y. Sano, and C. Genzel, "Investigation on the surface and near-surface characteristics of Ti-2.5Cu after various mechanical surface treatments," Surface and Coatings Technology, vol. 205, no. 12, pp. 3644-3650, 2011.

[30] P. Peyre, X. Scherpereel, L. Berthe et al., "Surface modifications induced in 316L steel by laser peening and shot-peening. Influence on pitting corrosion resistance," Materials Science and Engineering A, vol. 280, no. 2, pp. 294-302, 2000.

[31] T. M. Yue, C. F. Dong, L. J. Yan, and H. C. Man, “The effect of laser surface treatment on stress corrosion cracking behaviour of 7075 aluminium alloy," Materials Letters, vol. 58, no. 5, pp. 630-635, 2004.

[32] M. M. Pariona, V. Teleginski, K. D. Santos, E. L. R. Dos Santos, A. A. De Oliveira Camargo De Lima, and R. Riva, "AFM study of the effects of laser surface remelting on the morphology of Al-Fe aerospace alloys," Materials Characterization, vol. 74, pp. 64-76, 2012.

[33] C. Vargel, Corrosion of Aluminim, Elsevier Science, San Diego, Calif, USA, 2004.

[34] P. Peyre, C. Carboni, P. Forget, G. Beranger, C. Lemaitre, and D. Stuart, "Influence of thermal and mechanical surface modifications induced by laser shock processing on the initiation of corrosion pits in 316L stainless steel," Journal of Materials Science, vol. 42, no. 16, pp. 6866-6877, 2007.

[35] H. Krawiec, V. Vignal, H. Amar, and P. Peyre, "Local electrochemical impedance spectroscopy study of the influence of ageing in air and laser shock processing on the microelectrochemical behaviour of AA2050-T8 aluminium alloy," Electrochimica Acta, vol. 56, no. 26, pp. 9581-9587, 2011.

[36] C. N. Panagopoulos, E. P. Georgiou, and A. G. Gavras, "Corrosion and wear of 6082 aluminum alloy," Tribology International, vol. 42, no. 6, pp. 886-889, 2009.

[37] Y. Liu and Y. F. Cheng, "Role of second phase particles in pitting corrosion of $3003 \mathrm{Al}$ alloy in $\mathrm{NaCl}$ solution," Materials and Corrosion, vol. 61, no. 3, pp. 211-217, 2010.

[38] Z. Nikseresht, F. Karimzadeh, M. A. Golozar, and M. Heidarbeigy, "Effect of heat treatment on microstructure and corrosion behavior of Al6061 alloy weldment," Materials and Design, vol. 31, no. 5, pp. 2643-2648, 2010.

[39] R. Ambat, A. J. Davenport, G. M. Scamans, and A. Afseth, "Effect of iron-containing intermetallic particles on the corrosion behaviour of aluminium," Corrosion Science, vol. 48, no. 11, pp. 3455-3471, 2006. 

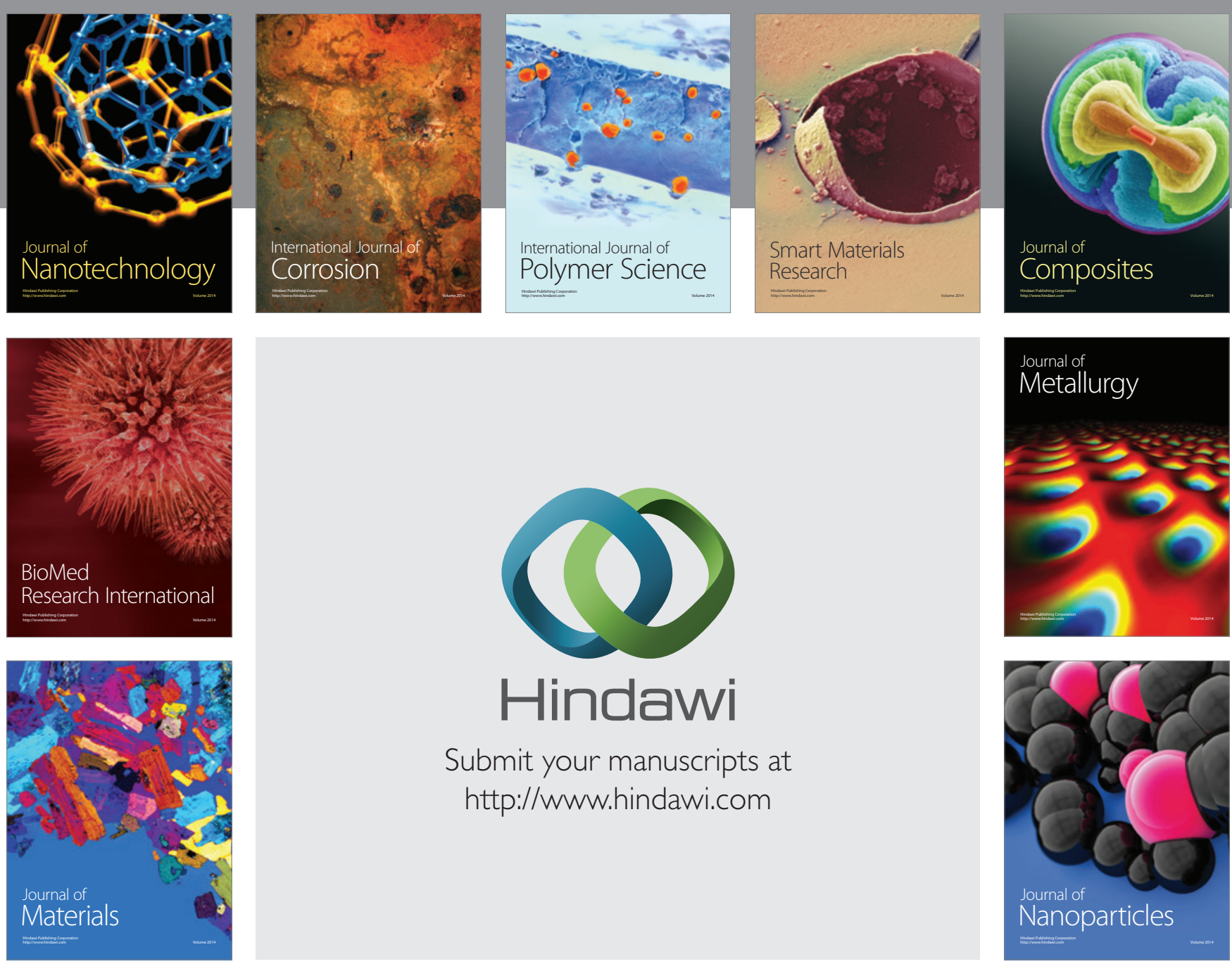

Submit your manuscripts at http://www.hindawi.com
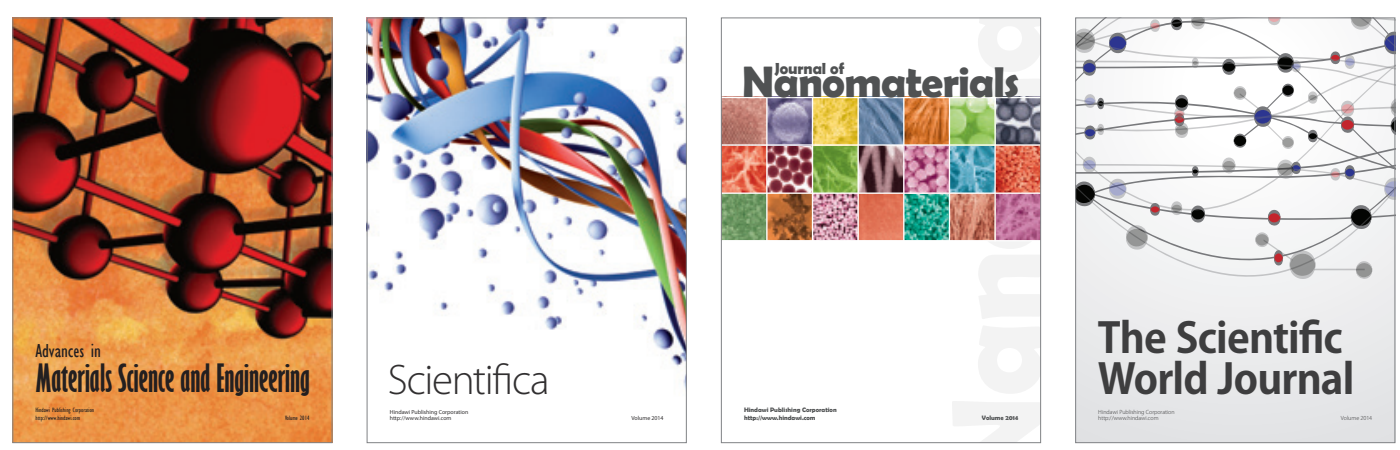

\section{The Scientific World Journal}
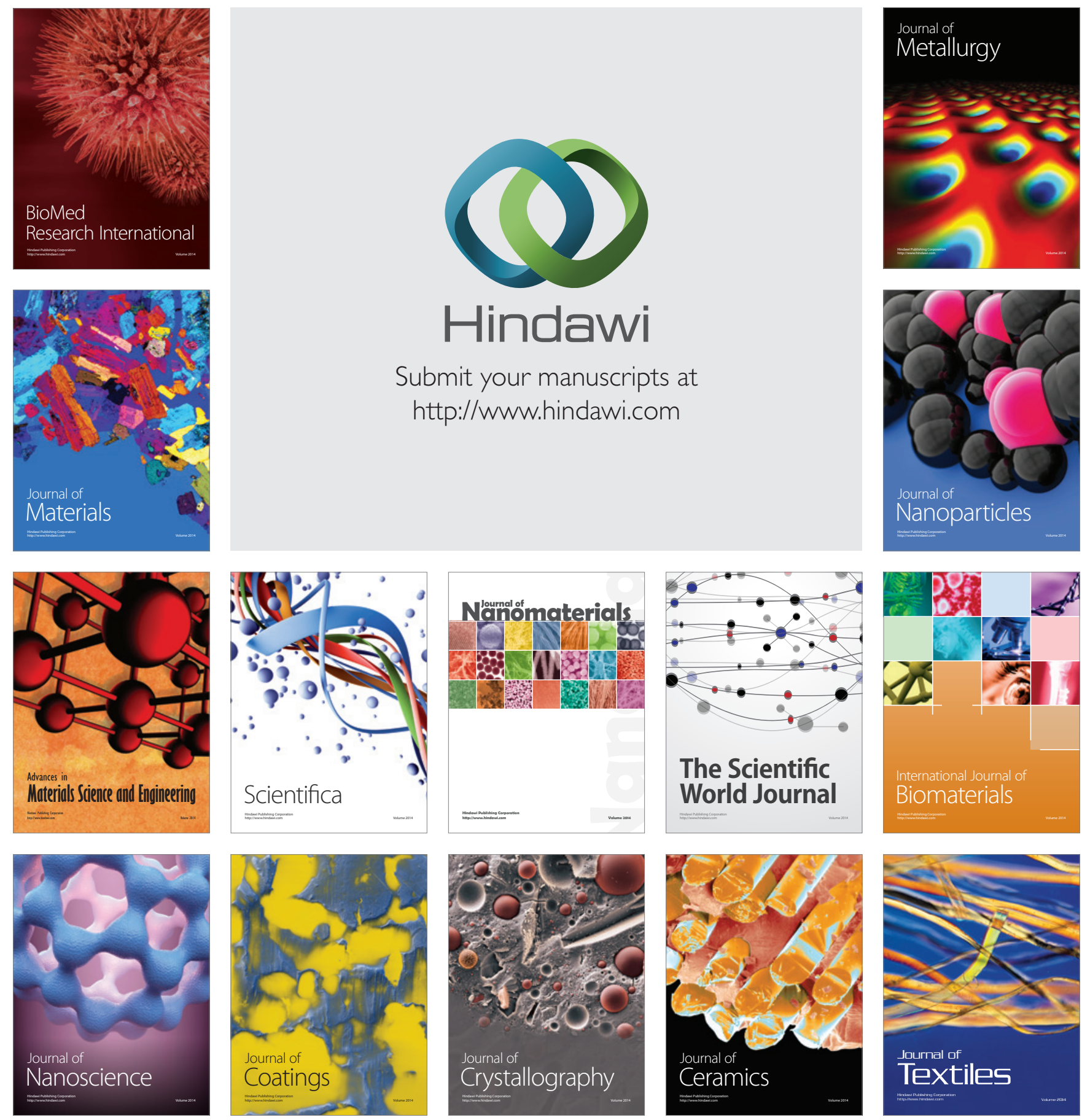